\title{
The David Middleton Reed Collection of Chinese Studies
}

A special area-studies library can develop in one of three ways. It can be comprehensive, amassing everything published in the field; it can be selective, narrowing its scope to one small part of the subject at hand; or, it can be both comprehensive and selective, gathering key works that touch on a broad range of topics. The David Middleton Reed Collection of Chinese studies at The University of Iowa has chosen the last course, striving to acquire important materials that support research throughout the broad spectrum of sinology.

The Reed collection was begun in 1977 when Harold L. and Virginia Middleton Reed donated a library of 538 volumes owned by their late son, David Middleton Reed, a budding scholar of Chinese philosophy at Stanford University. Since that time they have supported the growth of the collection with yearly monetary contributions matched by funds from the General Electric Company.

The core of David Reed's library is the Jen shou pen erh shih wu shih (The 25 official histories of China) (T'ai-pei: Erh shih wu shih pien k'an kuan, 1955-1958. 466 volumes) ${ }^{1}$ Each of these standard histories covers one dynasty of pre-Ch'ing China. It begins with the Shih chi (Record of history) compiled by Ssu-ma Ch'ien, the great scholar of Han China whose cyclical theory of history set the tone for later historiography throughout East Asia. It ends with the Ming shih (History of the Ming dynasty). The number of official histories has varied as new ones were added. By the late eighteenth century there were altogether 22 recognized works, but the retrieval of the earlier T'ang and Five Dynasties chronicles brought the total to 24 , which became 25 after imperial recognition of the Yüan shih (History of the Yüan dynasty). These vast works, ordered by the emperor of the time, tended to be more and more standardized as

\footnotetext{
1 Of the two most commonly used systems of Chinese transliteration, I prefer the pinyin system. I have chosen the Wade-Giles system, however, because that is the one followed by The University of Iowa Libraries.
} 
they became the collective effort of large editorial boards, ${ }^{2}$ but they are, nevertheless, the primary research tool used by scholars of pre-modern China. Although this edition, published under the auspices of Chiang Kai-shek, has been somewhat supplanted by an annotated edition issued by Chung-hua shu chü, Pei-ching, from the 1950s to the 1970s, it is still a valuable source of classic Chinese historiography.

The second large work in the original Reed library is the Shih san ching chu shu (The annotated 13 Confucian classics) (T'ai-pei: s.n., 196-? 70 volumes). All education in traditional China centered on these classics, and all aspiring government officials had to know them by rote in order to pass the imperial examinations. Covering Confucian thought on cosmology, ethics, and government, they include Confucius's own $\mathrm{Ta}$ hsüeh (Great learning), Chung yung (Doctrine of the mean), Lun yü (Analects), and Ch'un ch'iu (Spring and autumn annuals) as well as the I ching (Book of changes) - a divination manual, the Shang shu (Book of documents) - early ideas on the right to rule and the moral laws of government, the Shih ching (Book of odes) - a collection of 300 ancient folk songs, the I li (Book of rituals), the Chou li (Record of Chou)-an account of early Chou as an ideal state, the $L i$ chi (Record of ritual), the Hsiao ching (Book of filial piety), the Erh ya-a glossary of words in the Confucian classics, and the Meng-tzu (Book of Mencius). This edition, a reprint of an annotated 1815 publication, brings to the reader the gamut of traditional Confucian philosophy.

The last work in the kernel library is the $T z$ 'u hai (Sea of words) (T'ai-pei: T'ai-wan Chung-hua shu chü, 1967. 2 volumes). This is the standard Chinese-Chinese dictionary used in present-day China and Taiwan.

The first item that was added to the core collection was the Han wen ta hsi (Great collection of Chinese letters) (T'ai-pei: Hsin wen feng ch'u pan kung ssu, 1978. 22 volumes). While enlarging sources on Chinese philosophy and history, this collection turns also to literature. The philosophy section repeats the major Confucian works and also includes other traditional philosophers: Kuan-tzu, Han Fei, Lao-tzu, Chuang-tzu, Mo-tzu, Hsün-tzu, and Hui-nan-tzu. The history section has an annotated criticism of Ssu-ma Ch'ien, the Shih pa shih lüeh (Abridged 18 official histories) by Tseng Hsien-chih, and the Sengokusaku seikai (Critical edition of the Warring States chronicle) by Yokota Koretaka. The literature section contains the $K u$ wen chen pao (Treasures of ancient literature) by Huang Chien, the $K u$ shih shang hsi (Appreciation of

\footnotetext{
${ }^{2}$ Endymion Wilkinson. History of Imperial China: A Research Guide. Cambridge, Massachusetts: Harvard University Press, 1973, p. 73.
} 
ancient poetry) by Chang Yu-ku, the T'ang shih hsüeh (Study of T'ang poetry) by Li P'an-lung, the T'ang Sung pa chia wen (Collection of eight T'ang and Sung writers), and the Ch'u $t z$ ' $u$, a dictionary of Han Chinese. This collection, reprinted from an edition published by Fuzanbô., Tokyo, 1909-14, is annotated in both Chinese and Japanese and is especially valuable not only because it gathers into one set a fine sampling of Chinese scholarship, but also because it is a survey of the best of traditional Japanese sinology.

One of the major sources for the study of early Chinese language and culture is the inscriptions carved on ancient bronze vessels. Whereas in most cultures primary sources for the study of early civilization have long ago perished, these inscriptions, written in Old Chinese using a script now archaic, make up a vast record of life at the beginning of Chinese cultural awareness and also serve as a textbook of Old Chinese grammar. Esteemed as great works of art, these vessels have been scattered throughout the world so that scholars wishing to study their inscriptions have had to have the means to travel widely. A subsequent addition to the Reed collection, the Chung Jih Ou Mei Ao-niu so chien so t'a so mo chin wen hui pien (Rubbings and hand copies of bronze inscriptions in Chinese, Japanese, European, American, and Australasian collections) by Noel Barnard and Cheung Kwong-Yue (Taipei: Yee Wen Pub. Co., 1978. 10 volumes) has sought to make this research less difficult. The following list of the countries from which rubbings were collected shows how extensive this work is: U.S.A., England, Japan, New Zealand, Germany, France, Hong Kong, Denmark, Australia, China, Taiwan, Switzerland, Canada, and Singapore. Indeed these volumes of 1,820 inscriptions are "the largest assembly of inscription rubbings and hand copies compiled and published since 1936." 3 Written in both Chinese and English, this collection has the added value of giving a bibliographical background of each entry and a listing of the present whereabouts of the parent vessels.

Without bibliographies, research is crippled. The Shu mu lei pien (Collection of bibliographies) (T'ai-pei: Ch'eng wen ch'u pan she, 1978. 144 volumes) helps to meet this need. The editors, Yen Lin-feng and colleagues, have collated classic Chinese and Japanese bibliographic works, combined with modern studies. This work has detailed information on public and private collections and a list of libraries holding important works. The ten major headings within the set are catalogs of public depositories, of private collections, of special collections, bibliographies of collectanea, prefaces, colophons, editions, indexes, biblio-

\footnotetext{
${ }^{3}$ Noel Barnard and Cheung Kwong-Yue. Chung Jih Ou Mei Ao-niu so chien so t'a so mo chin wen hui pien. Taipei: Yee Wen Pub. Co., 1978, p. 8.
} 


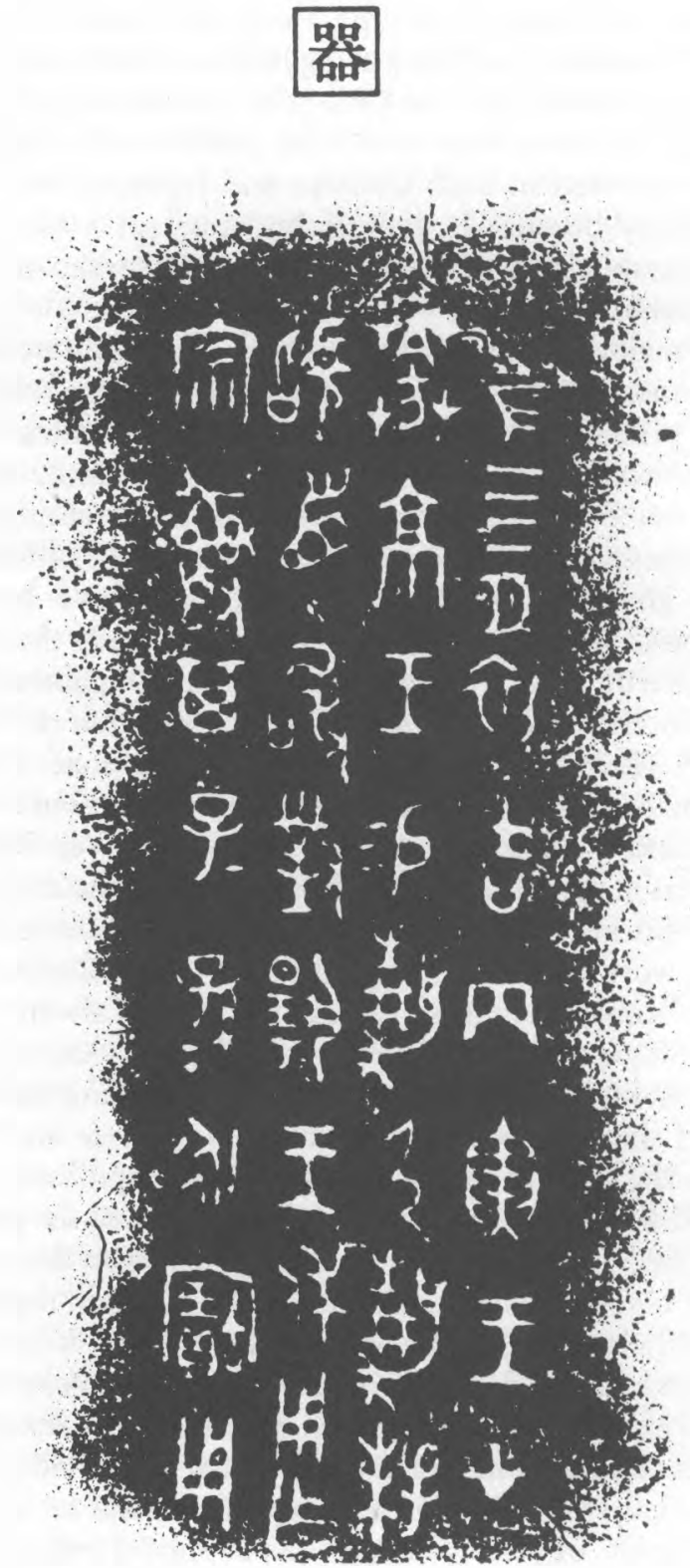

One of the 1,820 rubbings in the work by Noel Barnard and Cheung Kwong-Yue included in the Reed collection. This rubbing from a bronze wine vessel now in the National Palace Museum, Taipei, clearly retains the pictorial qualities of the original Chinese writing system. 
graphic essays, and Japanese bibliographies. An added value to these volumes is that they include both Chinese and Japanese sources.

The discovery of the library at Tun-huang in Kansu, China, was both a triumph and an imperialistic tragedy of the early years of this century. This library, containing manuscripts dating from the beginning of the fifth century to the end of the tenth century, was sealed in the caves of a Buddhist monastery probably during the first part of the eleventh century. There it lay until 1900 . One night that summer an aide to the Taoist monk Wang Yuan-lu, knocking his pipe against a wall of the cave, thought he heard an echo. He called Wang, and together they unsealed the entrance. What they saw was a chamber piled high with manuscripts and painted scrolls. A later survey would show that most of the holdings were Buddhist scriptures. There were also Confucian and Taoist writings, public and private documents, philosophical and historical treatises, phonetic and rhyme books, music scores, poems and essays, novels, land deeds, and calendars written in Chinese, Tibetan, Sanskrit, and Central Asian languages. ${ }^{4}$

Sir Aurel Stein, a Hungarian-born British subject who had gone out to India first in the Indian Educational Service and then as a member of the Indian Archaeological Survey, heard rumors of the discovery during his explorations in central Asia. He arrived in Tun-huang in 1907. After days of threatening and begging, ${ }^{5}$ Stein was allowed to take 24 cases of scrolls and five cases of art objects back to the British Museum. ${ }^{6}$ Since he could not read Chinese, he picked at random only scrolls in the most perfect condition.

Next came Paul Pelliot in 1908, up from his post as professor of sinology at Hanoi. He managed to cart away about one-fourth of the remaining collection. Since he could read Chinese, he wisely chose quality materials that mostly bear dates or signatures. Finally Tachibana Suichō and Yoshikawa Koichirỗ were sent out from Japan in 1912 and returned with their share for the National Diet Library. Stein came back in 1914 to add to his first takings. Looting scattered scrolls to collectors' markets in other parts of the world until the remaining part of the collection was brought to the National Peking Library in the 1920s. The Nationalist government carried a small share of the Chinese holdings with them to Taiwan in 1949.

A rough count shows that the present collection is housed as follows: British Museum, 9,000 scrolls; National Peking Library, 8,000 scrolls;

${ }^{4}$ Su Ying-hui. Tun-huang lun chi. T'ai-pei: Hsüeh sheng shu chü, 1969, p. 25.

${ }^{5}$ Aurel Stein. On Ancient Central Asian Tracks. London: Macmillan, 1933, pp. 203-11.

- Su Ying-hui. Tun-huang, p. 23. 
Bibliothèque Nationale, 1,500 scrolls; National Diet Library, 430 scrolls; National Central Library at Taipei, 150 scrolls; with the remainder held at institutions throughout Europe and America. ${ }^{7}$

Up to the present time, each holding institution has jealously guarded its collection, making research well-nigh impossible. The Tun-huang pao tsang (The collection of Tun-huang treasures) (T'ai-pei: Hsin wen feng ch'u pan she, 1981- ; 150 projected volumes, 130 volumes completed) will stop this gap. When the printing of this set is completed, scholars will have at their fingertips fine, clear reproductions of these fragile but invaluable materials.

The latest addition to the Reed collection, the Wen yüan ko Ssu k'u ch'üan shu (The great encyclopedia of the four treasuries at the Wen yuan pavilion) (T'ai-pei: Shang wu yin shu kuan, 1983- ; 1,500 volumes, 1,211 volumes completed), is one of the largest publishing efforts ever undertaken in Taiwan. Compiled during the reign of the Ch'ing Ch'ien-lung emperor, this collection comprises 3,460 major works. The compilation alone involved the labor of more than 300 of the foremost scholars of the time. In 1772 the emperor ordered a collection of books from throughout China for the project. These books, joined with books from the imperial library, were copied by some 2,800 copyists, a project which was completed only in $1781 .{ }^{8}$ This is by far the most comprehensive collection of traditional Chinese scholarship and includes the broadest sampling of works in a wide variety of learning, such as history, ethnography, social sciences, political science, fine arts, agriculture, and the natural sciences. Printed on quality paper and faithfully reproducing the fine calligraphy of the original scribes, this collection brings into one room the major works of 5,000 years of Chinese scholarship.

Because of a pledge of future support from the Reeds, the David Middleton Reed Collection will continue to add large, comprehensive publications, expanding into the fields of modern literature, art, and popular culture.

${ }^{7}$ Heibonsha daihyakka jiten. Tokyo: Heibonsha, 1984, v. 10, p. 675.

${ }^{8}$ The Wen-yuan Pavilion Ssu-k'u ch'uan-shu. Taipei: Commercial Press, 1982, p. 24. 


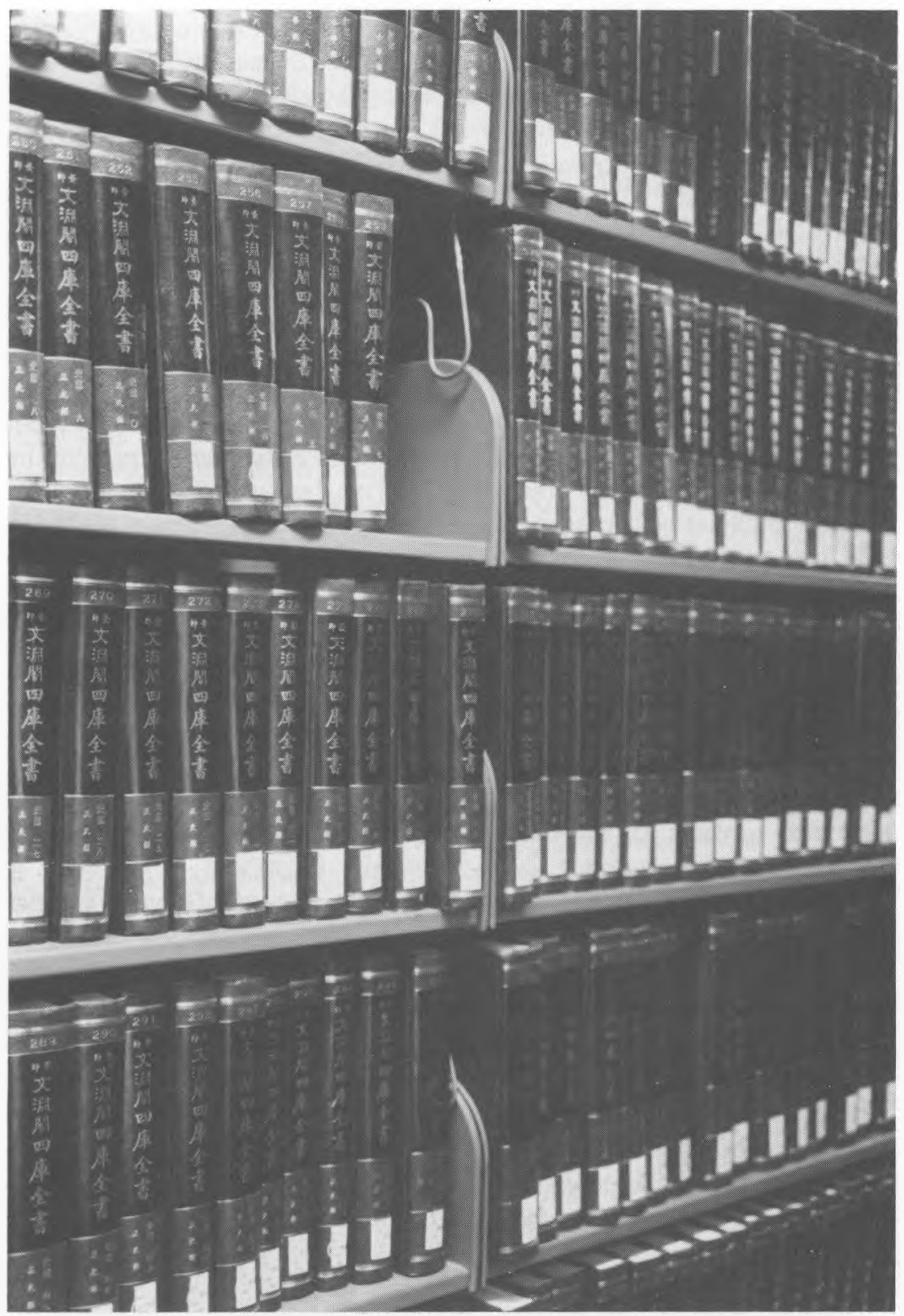

A wall of Chinese books from the David Middleton Reed Collection in the Oriental Reading Room, The University of lowa Libraries. 